\title{
Anxiety and depressive disorders in children and adolescents suffering from diabetes mellitus
}

\section{Anksiozni i depresivni poremećaji u djece i adolescenata oboljelih od diabetes mellitus}

\author{
Ana Đorićíc ${ }^{*}$, Dejan Stevanović2 ${ }^{2}$ Rajna Knez ${ }^{3}$
}

${ }^{1}$ Odsjek za psihologiju, Filozofski fakultet, Sveučilište u Rijeci, Rijeka

${ }^{2}$ Klinika za neurologiju i psihijatriju za decu i omladinu, Beograd, Srbija

${ }^{3}$ Katedra za psihijatriju i psihološku medicinu, Medicinski fakultet, Sveučilište u Rijeci, Rijeka

*Corresponding author:

Ana Đorić, mag. psych.

Faculty of Humanities and Social Sciences University of Rijeka

Sveučilišna avenija 4, 51000 Rijeka

e-mail: ana.djoric.cpp@uniri.hr

\begin{abstract}
Diabetes mellitus (DM) and mental health problems are frequently co-occurring conditions. Anxiety and depressive disorders are the most common mental disorders that accompany DM. These conditions could have severe consequences in children and adolescents suffering from DM. Thus, it is important to pay additional attention to them. This article provides an overview of prevalence rates of DM and co-occurring anxiety and depression, as well as understanding the etiology and treatment options for anxiety and depressive disorders in children and adolescents with DM.
\end{abstract}

Key words: anxiety disorders; depression; diabetes mellitus

Sažetak. Diabetes mellitus (DM) i psihički poremećaji često su u komorbiditetu. Anksiozni i depresivni poremećaji najčešći su duševni poremećaji koji prate DM. Ovi mentalni poremećaji mogu imati ozbiljne posljedice za djecu i adolescente koji boluju od DM-a, stoga je važno posvetiti im dodatnu pozornost. $\mathrm{U}$ radu donosimo kratak pregled prevalencije DM-a i komorbiditetnih anksioznih i depresivnih poremećaja te razumijevanje etioloških karakteristika. Ukratko smo se osvrnuli i na mogućnosti liječenja djece i adolescenata koji imaju DM i anksiozni odnosno depresivni poremećaj.

Ključne riječi: anksiozni poremećaji; depresivni poremećaji; diabetes mellitus

http://hrcak.srce.hr/medicina 


\section{INTRODUCTION}

Diabetes mellitus (DM) is a metabolic disease originating due to insulin secretion defects, insulin action defects, or both ${ }^{1}$. There are three main types of diabetes: Type 1 diabetes (T1D), Type 2 diabetes (T2D) and Gestational diabetes ${ }^{2}$. T2D is the most common type of DM, which usually affects adults, but is also prevalent in paediatric population $^{2}$. Reliable data concerning epidemiological rates are scarce, but it appears that T2D in childhood could soon become a global public health issue $^{2}$. T1D can originate in any age, but its onset is usually in childhood or young adulthood ${ }^{2}$. Moreover, T1D is one of the most common endocrine and metabolic conditions in childhood, with the number of children diagnosed increasing every year $^{2}$. The International Federation of Diabetes (IFD) estimated that the number of children younger than 15 affected by T1D in 2015 was about 542 000, with an estimated increase around $3 \%$ per year and with 86000 newly diagnosed cases per year (the highest incidence rates being in Finland, Sweden and Kuwait) ${ }^{2}$.

\section{MENTAL HEALTH PROBLEMS AND DM}

Mental health problems and T1D are frequently co-occurring conditions throughout childhood and adolescence. Current reports record a comorbidity rate of mental health disorders at about 20 to $50 \%$ in children and adolescents suffering from $\mathrm{DM}^{3}$. It is important to state that not all studies report a significant increase in psychopathology in patients with $\mathrm{DM}^{3}$, albeit the risk does tend to be greater in diabetes suffering, compared to healthy children and adolescents ${ }^{4}$. Considerable evidence of an association between psychological disorders and juvenile diabetes is nowadays present ${ }^{5}$. In addition, studies show that adolescents with DM tend to have more severe internalizing symptoms, as opposed to healthy adolescents ${ }^{6}$.

Mood disorders are the most frequent co-occurring diagnosis in youth with $\mathrm{T}^{6} \mathrm{D}^{6}$, whereas the most frequent mental health problems in youth with DM are depression followed by anxiety ${ }^{5}$; characterized by different emotional, cognitive, and behavioral changes that affect the individual's quality of life and capacity for everyday functioning. As a group of different conditions, anxiety disorders are characterized by excessive fear and anxiety, whilst depressive disorders are characterized by the presence of sad, empty, or irritable $\operatorname{mood}^{7}$.

Although anxiety and depression seem to have an important role in determining adaptation to the disease, their relationship to metabolic control still isn't clear ${ }^{5}$. Specifically, studies show that depression in youth has been associated with rel-

Symptoms of anxiety and depressive disorders frequently co-occur with paediatric diabetes mellitus (DM) and seem to be associated with significant medical complications, poor treatment adherence, and consequently impaired quality of life. Various biological, psychological, and environmental links are implicated in the relationship between anxiety and depressive symptoms and DM.

evant outcomes regarding the treatment of T1D, such as adherence to DM regimen in glucose monitoring and poorer metabolic control $^{8}$. In some studies, depression was associated to poorer insulin injection and dieting ${ }^{9,10}$, as well as psychological outcomes such as poor quality of life ${ }^{11}$ and low self-esteem ${ }^{9,12}$. Studies show that $20 \%$ of metabolic control variance could be explained by depressive symptoms and that these children have lesser glycaemic control ${ }^{13}$. Moreover, there seems to be an increase in suicidal ideation in adolescents with T1D ${ }^{14}$.

It is necessary to understand the relationship between DM, anxiety and depressive symptoms in children and adolescents in order to prevent developing potentially serious outcomes that can arise from this comorbidity. Thus, this article provides an overview of prevalence rates of DM and co-anxiety and depressive disorders, as well as understanding the etiology and treatment options.

\section{PREVALENCE RATES OF ANXIETY AND DEPRESSIVE SYMPTOMS IN DM}

Anxiety and depressive symptoms in children and adolescents with T1D tend to appear more often 
than in healthy peers ${ }^{8,15}$. A study conducted by Kokkonen and Kokkonen ${ }^{16}$ found only a moderate prevalence of depression in children and adolescents. Nevertheless, they concluded that DM in childhood itself could not be considered a risk factor for mental health in young adulthood. The disease could only strengthen the severity of psychological symptoms, especially depression, which seems to be a severe affective disorder when co-occurring with $\mathrm{DM}^{16}$. Follow-up longitudinal studies made by Kovacs and colleagues ${ }^{17}$ found that the first year of T1D is associated with highest incidence of psychiatric disorders in general, but with anxiety and depressive disorders in particular. In a ten year-span, more than two out of five children suffering from DM experienced one episode of mental health disorders, whereas one out of four developed depression ${ }^{17}$. Whereas mental health problems seem to prevail quite often throughout a ten-year span, there also seems to be an initial increase of depressive symptoms after DM diagnosis. Grey, Whittemore and Tamborlane ${ }^{8}$ found that children with DM reported significantly greater levels of depressive distress at the time of DM diagnosis and at the end of a second year follow-up, compared to children without DM. They also found a prevalence of depressive symptoms affecting up to every fifth adolescent with T1D registered in clinical settings ${ }^{8}$. Furthermore, they found that the duration of DM significantly correlated with depressive symptoms in a U-shaped manner. In other words, earlier post diagnosis years and ten-year duration of T1D was associated to more depressive symptoms, whereas in the period between four to nine years post diagnosis depressive symptoms were less common ${ }^{8}$.

A meta-analytic report, which included 22 studies, indicated that children suffering from DM, compared to peers, experience elevated levels of depression, anxiety and psychological distress, although the effect was found to be small to medi$\mathrm{um}^{18}$. Furthermore, it showed that children with poor metabolic control amongst DM patients manifest larger anxiety and psychosocial distress, meaning that poorer control of the disease could lead to mental problems ${ }^{18}$. Another systematic review and meta-analysis ${ }^{19}$, which included 14 studies, showed that the occurrence of anxiety symptoms is raising up to every third child and adolescent suffering from T1D. Herzer and colleagues $^{20}$ also reported a correlation between the onset of depression and anxiety in patients with DM, meaning that they tend to appear conjointly. Given the vast prevalence and potential severity of mental health comorbidities, mental screening is a procedure advised to become a basic part of clinical practice standards in children and adolescents with DM, in addition to medical examination and treatment ${ }^{4,21}$.

FACTORS RELATED TO DEVELOPMENT

OF ANXIETY AND DEPRESSIVE SYMPTOMS

Risk factors that increase the likelihood of depression and anxiety among children and adolescents suffering from DM are many, and are conceptualized as negative experiences, demographic variables, environmental characteristics and biological mechanisms. Below we give an overview of the factors most commonly reported in literature.

\section{DM as a stressful life experience}

DM itself, especially T1D, is considered to be a stressful life experience and could cause significant depressive symptoms ${ }^{8}$. Nevertheless, even if $\mathrm{DM}$ is shown to be a risk factor for depression onset $^{18}$, the relationship could be bidirectional, since it is possible for mental health problems to also cause poorer metabolic control ${ }^{22,23}$. A few authors state that DM is not a risk factor for depression, although it can strengthen the severity of psychological symptoms ${ }^{19}$. The nature of the relationship between DM and mental problems remains unclear, and more research determining causal relationships is needed.

Aside from mental health problems, studies show that children with T1D are also at high risk for developing behavioural problems ${ }^{24,25}$. Young adults with DM are often viewed as different and stigmatized, and, in the age they find themselves in, such discrimination from their peers and consequent stressful experiences can lead to negative well-being ${ }^{26}$. Adolescents suffering from T1D, 12 to 15 year-olds, were found to experience more social anxiety symptoms than healthy adolescents ${ }^{27}$, since it is possible that peer evaluation 
and support are somewhat jeopardized by the disease itself, and the participation in social activities is scarce.

\section{Negative (self-) evaluation}

Young adults suffering from DM tend to evaluate negatively their competence regarding self-care ${ }^{28}$. Various experiences, such as negative evaluation and self-feedback could create a negative feedback loop, which increases the likelihood of anxiety and depressive disorders in $\mathrm{DM}^{28}$. Negative interpretation of events and self-competence could therefore lead to mental health problems. Negative experiences and symptoms could interact and lead to a worsening in mental health, and therefore increase the likelihood of depression and anxiety onset in paediatric DM, a hypothesis that needs to be further examined.

\section{Age and gender}

Adolescents are more prone to depression than children, since it is a period of rapid change ${ }^{8,29}$. Gender, especially in the period of adolescence, is also a factor. Girls are more prone to and manifest depression symptoms ${ }^{30}$, in respect to boys, although the evidence is still contradictory ${ }^{8}$. Research suggests that girls tend to report more anxiety, depression and internal distress symptoms ${ }^{10}$. This could be a consequence of different responses to life stressors commonly experienced in adolescence, not DM exclusively. Girls tend to internalize stress, which can lead to more dysphoric feelings ${ }^{10}$. It also seems that gender differences tend to enhance during adolescence, with coping strategies such as rumination leading to enhanced depressive symptoms in girls, compared to boys ${ }^{31}$, in respect to childhood.

\section{Family environment}

The family context is a very important factor in understanding how children adjust to a chronic illness and cope with it. A cohesive family environment can benefit a child's well-being, with parents being supportive and flexible about their child's needs ${ }^{32}$. Studies show that lack of parenting skills and family conflict can lead to internalizing disorders in adolescents ${ }^{3}$. The family environment following DM diagnosis, especially T1D, can become emotionally charged and result in conflict among family members, which can lead to psychological distress, such as anxiety and depressive disorders in children ${ }^{13,20,33}$. In the presence of "diabetes-specific family conflict", anxiety seems to be triggered or heightened, leading to poor glycaemic control via diabetes-related behaviour such as dieting, exercising, etc ${ }^{20}$. Studies show that family dynamics change after the diagnosis of T1D, leading to problems described earlier, since DM tends to influence the family's well-being ${ }^{34}$.

\section{Parenting type}

Adolescence is a turbulent developmental phase, with development tasks such as growing autonomy and independency ${ }^{28}$. It is the same with DM maintenance and the independence the child gradually grows in health behaviours themselves. Parents' role is to be supportive of the adolescent and maintain a level of involvement that allows the child to become more independent, but also making certain that medical requirements are present $^{33,35}$. Over-controlling parenting is related to depressive outcomes in children with $\mathrm{DM}^{35}$. On the other hand, supportive parenting with a moderate level of firm control is related to a range of positive child outcomes ${ }^{35,36}$, better glycaemic control and fewer depressive symptoms ${ }^{37}$. Furthermore, research done on mothers of children with DM found a significant increase in mothers' manifestation of anxious and depressive symptoms ${ }^{37}$. Such maternal symptoms of distress are further shown to be related to over-involved parenting, which can lead to worsening of an adolescent's well-being ${ }^{35}$. Consequently, higher levels of maternal control tend to relate to higher depressive symptoms in female diabetic adolescents, which accounts for gender differences in the outcomes of parenting control ${ }^{35,38}$.

It is therefore indicative that psychological control in parenting could be a risk factor for depressed mood amongst chronically ill adolescents ${ }^{39}$, whereas acceptance could be a protective factor for mental disorders ${ }^{35}$. Firm control, which is perceived as unwanted interference in periods of autonomy development, is also a factor that may contribute to the increase of depressive symptoms, but it appears to occur amongst older adolescents ${ }^{35,40}$. Amongst younger adolescents, firm 
control could be a protective factor, since they are still depending on maternal assistance ${ }^{35,40}$.

\section{Parental mental health}

In general, evidence suggests that there is also a strong relationship between mothers and children's depressive symptoms in school-aged children ${ }^{41}$, with mothers' depression being a major risk factor in children's depression ${ }^{24}$. Mothers with higher level of depressive symptoms tend to provide lesser support and warmth, potentially leading to lower psychosocial adjustment of the child and adolescent ${ }^{41,42}$. Paternal and maternal stress is also related to depressive symptoms in adolescents with $\mathrm{T}^{4} \mathrm{D}^{43}$.

\section{Biological mechanisms}

Although many studies address the pathophysiological relationship between the onset of DM and depression, mechanisms by which depression and DM relate to each other are still to be established $^{44}$. There are evidence that glutamic acid decarboxylase autoantibodies (GADA), which are related to $D M$, could influence the synthesis of the gamma-aminobutyric acid (GABA), which in return is shown to be associated to depressive symptoms and cognitive dysfunction ${ }^{45}$. The link between depression and DM can also have biological connections such as dyslipidaemia, which seems to be a biological correlate of depression and DM in adolescents ${ }^{19}$. There is preliminary evidence that higher levels of depression are associated with metabolic abnormalities and systemic inflammation $^{46}$. T1D may contribute to emotional and biological disruptions, so that depression exacerbates dyslipidaemia ${ }^{46}$. It is also assumed that depression itself is a moderate risk factor for developing DM in young adults, either directly or indirectly ${ }^{47-49}$. Irving and colleagues ${ }^{47}$ explained other biological mechanisms. For one, it is shown that genetic predisposition for T2D can predict levels of depressive symptoms. High depressive symptom scores of children with a familial history of DM have also been noted. One possible explanation is that the duration of generational history of DM might have provided chronic ongoing stress, which may have manifested as depressive symptoms. Another mechanism proposed is the connection between depression and the hypoth- alamopituitary adrenal axis ${ }^{47}$. Specifically, depression tends to affect the hypothalamopituitary adrenal axis, which can lead to elevated glucose levels and decreased glucose uptake, leading to manifestation of T2D.

\section{ADHERENCE TO TREATMENT}

Problems with non-adherence are a common difficulty in DM that can potentially lead to severe medical complication outcomes ${ }^{8,50}$. Adolescents with T1D tend to demonstrate poor diabetes management behaviour, making them a risk group for unhealthy outcomes regarding $\mathrm{DM}^{20}$. Depressive symptoms in adolescents with DM are associated to poor adherence to treatment ${ }^{8}$, often leading to scarce metabolic control ${ }^{22}$, as well as higher levels of $\mathrm{HbA} \mathrm{c}^{23}$. Regarding that, psychosocial factors of DM described earlier could be one of the most influential factors affecting care and treatment of DM in children $^{21,50,51}$. Studies differentiate high-risk children from moderate-risk children for negative disease outcomes and the accompanying characteristic behaviour patterns ${ }^{50}$. Higher-risk children are more problematic, since they tend to have a higher incidence of poor coping skills, behaviour problems and a significant delay in developmental phases ${ }^{50}$. High-risked children have a tendency of coping with stress by reacting emotionally, avoiding problems and not seeking help, as well as indulging in undesirable behaviour, leading to poorer adherence to treatment ${ }^{50}$. Thus, one of the factors contributing to non-adherence in adolescents with depression is ineffective response to daily levels of stress, leading to less engagement in health related behaviours and, on the other hand, a possible increase in $\mathrm{HbA} 1 \mathrm{c}^{52}$. Moreover, adolescents with depressive symptoms tend to overreact to acute stressors and have little problem-solving abilities, often leading to complications and the reoccurrence of depressive symptoms, which are in turn problematic for long-term DM management ${ }^{22}$. It also appears that depressive reactions to the illness itself can have a significant impact on families of children with DM, as well as an impact on treatment adherence itself ${ }^{8}$. Concerning the latter, studies show that depression in DM is associated to high- 
er rates of hospitalization post diagnosis ${ }^{23,53}$ and longer hospitalization duration ${ }^{23}$.

Treatment of DM sometimes requires rigid regimen. It is therefore relatively unpopular in the adolescent population, with data showing that two-thirds of adolescents are poorly managing their disease $\mathrm{e}^{54,55}$. Poor adherence to the tasks required for self-management can consequently lead to a suboptimal glycaemic control, with diabetic control decaying throughout the years, being lowest at ages 18-1954,56. Nevertheless, general individual differences in adherence to treatment exist ${ }^{57}$. One of the factors that might contribute to differences in medical behaviour is illness representation $^{57}$. Illness representation is a term conceptualizing a common sense belief about the illness itself, with four attributes in the background: identity (reported illness symptoms), cause (perceived biological, emotional, environmental and psychological factors that lead to the disease), consequence (beliefs regarding the impact of the illness on the patient's life), and control (beliefs about control of the illness and treatment control $)^{57}$. Self-management is considered to be a coping strategy for one's illness, with consequence and control being major predictors of adherence to DM regimen and treatment ${ }^{54,58}$. Furthermore, negative illness representation is shown to predict more anxiety and depression symptoms among adolescents with $\mathrm{DM}^{59}$. Additionally, fear of negative evaluation and lack of family support are considered as potential predictors of psychological maladjustment ${ }^{59}$. Fear of negative peer evaluation, especially in the context of visible physical symptoms of DM - such as shaking and fatigue could lead to anxiety ${ }^{59}$. Moreover, adolescents who perceive DM they are suffering from as having major consequences, tend to have more intense depressive symptoms, whereas illness identity (symptoms that occur) leads to higher anxiety and depressive symptoms ${ }^{59}$.

\section{TREATMENT OF DEPRESSION AND ANXIETY}

\section{IN DM}

\section{Medication}

Various antidepressants, such as fluoxetine, sertraline, citalopram, bupropion or nortriptyline, could be effective in reducing depressive symp- toms in adults with DM, with possibly no adverse effects on glycaemic control ${ }^{60}$. Some studies show that reducing depressive symptoms by antidepressants in patients with DM is associated not only with better health behaviour, but also with favourable outcomes in glycaemic control ${ }^{61,62}$. Although limited, there is evidence on the safety of antidepressants as related to glycaemic control, but when selecting an antidepressant clinicians should consider present diabetic complications and major side effects of different antidepressant groups $^{63}$. A general recommendation for adult patients is to use fluoxetine or sertraline for depression in DM suffering patients ${ }^{64}$. In terms of reducing depressive symptoms and improving functioning amongst children suffering from depression, fluoxetine is probably the best option to consider for pharmacological treatment for children and adolescents ${ }^{65}$, even if there are some safety concerns and there are no valid research studies to base recommendations on.

The effectiveness of antidepressants in treating anxiety and depressive disorders in paediatric DM has not been documented. Both fluoxetine and sertraline are part of selective serotonin reuptake inhibitors (SSRI), which are also the most prescribed medications to children and adolescents $^{66}$. In Croatia, among SSRI, sertraline seems to be the most frequently prescribed antidepressant for treating depression in children and adolescents, followed by fluvoxamine, tianeptine and others ${ }^{66}$. Fluvoxamine is also frequently used for the treatment of anxiety disorders in children and adolescents ${ }^{66}$.

\section{Psychotherapy}

There is evidence of efficient psychotherapeutic strategies targeting well-being, stress management, and self-management in DM, such as family therapy and self-reliance therapeutic or supportive approaches ${ }^{67-69}$. These techniques could help overcome different DM care challenges, such as adherence to treatment, mild psychological distress, or diabetic complications. Moreover, Bitsko and colleagues ${ }^{70}$ found that psychological intervention (focused on incorporating the family into the care of the child, behavioral aspects of medical management, and cognitive processing) significantly reduced $\mathrm{HbA} 1 \mathrm{c}$ over time, leading to better 
metabolic control in patients undergone psychological treatment. A wide palette of psychotherapy methods used in anxiety and depression treatment exists. However, we chose to address those methods whose efficiency has been examined in multiple studies, which specifically address interventions in children and adolescents suffering from DM.

Cognitive-Behaviour therapy. One of the widely used psychotherapy methods is Cognitive-Behaviour Therapy (CBT), which is often applied in or-

Mental health screening and interventions aimed at treating anxiety and depressive disorders in children and adolescents suffering from diabetes mellitus (DM) should be an added approach, in addition to medical treatment of DM. An interdisciplinary approach, with specific individually tailored treatment for patients, and treatment for patients' families, is advised.

der to reduce the negative effect of depression on a patient's well-being ${ }^{71}$. Probably the best option to consider for paediatric depressive symptoms are interpersonal therapy (IPT) or cognitive behavior therapy $(C B T)^{72}$. The basic idea of CBT is that symptoms closely relate to thoughts (cognition), actions and mood. The focus of CBT is to teach patients how to recognize and change maladaptive thoughts, which accompany various disorders, with adaptive ones. It also works on behavioural aspects and directly changes one's behaviour to certain stimulus. Consequently, depressive symptoms, especially in the form of cognitive distortions (a form of maladaptive thoughts), could be reduced ${ }^{71}$. In patients with DM, the same principle applies, since it seems that thought problems could be a discriminant factor of patients with DM and healthy youth, meaning that patients suffering from DM have more thought problems than healthy ones ${ }^{73}$. Studies show that the process undergoing CBT could lead to better glycaemic control, thus consequently indirectly influencing the patient's physical health ${ }^{74,75}$. A study conducted by Rossello and Jiménez-Chafey ${ }^{76}$ showed a significant decrease in depressive and anxious symptoms in patients with DM, as well as an improvement in self-concept and DM self-efficacy management after CBT treatment. Nevertheless, it failed to demonstrate a significant effect on glycaemic control. On the contrary, Lloyd and Brown ${ }^{74}$ found an increased likelihood for remission of depression in patients undergone $\mathrm{CBT}$, compared to the control group, as well as better glycaemic control after CBT treatment, compared to no CBT treatment. Ahmadi and colleagues ${ }^{75}$ also found a positive effect of CBT on symptoms of depression and anxiety, as well as better glycaemic control in children 6 to 14 years-old. It seems that learning about negative emotions and their relation to depression could lead to better understanding and better awareness of the condition children and adolescents with DM are coping with. In addition, education about the disease itself and the behaviour that is adequate, could lead to better control of the illness ${ }^{77}$. Shomaker and colleagues $^{77}$ found a decrease in depressive symptoms and stabilized insulin sensitivity at one-year follow-up in female adolescents at risk for T2D undergone CBT or health education, explaining that learning to deal with stress could lead to less depressive symptoms and better metabolic control. It is still unclear whether interventions for anxiety and depression influence DM characteristics, such as glycaemic control or others. CBT might be effective in reducing short-term and medium-term glycaemic control, without significant effects for long-term glycaemic control ${ }^{78}$. Interpersonal therapy (IPT). IPT focuses on reducing depressive symptoms by improving interpersonal functioning and dealing with interpersonal problems. It relies on focusing on exploration and clarification of feelings, improvement of communication skills, and cognitive-behavioral techniques $^{79}$. Among psychotherapies tested in children and adolescents with co-morbid depression in DM, IPT is shown to be beneficial at posttreatment and at follow-up ${ }^{80}$.

Psychosocial interventions. Psychosocial interventions that work individually, such as motivational interviewing, have shown some promising results in improving glycaemic control ${ }^{81}$. In addition, interventions such as coping skills training (CST) appear to have greater effects on adherence and glycaemic control ${ }^{82}$. CST focuses on a 
lifestyle within the context of DM, instead of just managing the disease. The goal is to increase an adolescent's sense of competency by retraining inappropriate or nonconstructive coping styles and forming more positive styles ${ }^{83}$. Studies show that psychological well-being improves in patients who undergo $\mathrm{CST}^{84}$.

Family interventions. Working with the family of the patient is also of great importance. Since children and adolescents suffering from DM rely greatly on their parent's aid, it could be of importance to work with parents in order to insure the quality of life of both the family and the patient. Interventions such as education about the course of illness and strategies on how to deal with the disease show improvement in metabolic control and better family functioning 84,85 . Paediatric diabetes care requires supportive and collaborative communication, with realistic expectations for youth ${ }^{86}$.

Peer interventions. An important aspect of psychological well-being is also friendship support, since friendship has a protective function for psychological health (both in adolescents with DM and healthy ones) and has implications for physical health among those with $\mathrm{DM}^{87}$. Regarding the latter, peer group intervention is also beneficial. Peers are more likely to provide emotional support and companionship in DM care ${ }^{84}$. Involving peers whilst also increasing their knowledge about DM and ways to offer support are effective means in treatment.

Multisystem therapy (MST). MST, a therapeutic intervention that takes place at home and partly consists of family interventions, is a promising approach in supporting adolescents with T1D. It is a treatment based on social and family system theories of behaviour. Interventions target the adolescent, the family, and the greater community involved in patient care. A Meta - analysis ${ }^{88}$ showed that MST is most effective within a population aged up to 15 . Ellis and colleagues ${ }^{89}$ found a significant increase in adherence after MST. Overall, MST is a rising and promising way to combat adherence issues in youth with $\mathrm{T}^{10} \mathrm{D}^{90}$.

\section{Treatment recommendation}

Due to the lack of clear guidelines, but considering the availability of different medications and psychological interventions for anxiety and depressive disorders, we would recommend the following general principles when dealing with these symptoms in paediatric DM, which are based on the Practice parameters of the American Academy of Child and Adolescent Psychiatry ${ }^{91,92}$. Psychoeducation, support, and case management are sufficient treatments for the management of uncomplicated or brief depression, mild anxiety or with mild psychosocial impairment in general. In children and adolescents with moderate to severe depression, chronic or recurrent depression, severe anxiety, considerable psychosocial impairment, suicidality, agitation, and psychosis, supportive psychotherapy and case management are usually not adequate. In such cases, more specific types of psychotherapy and/or pharmacological treatment are indicated.

Nevertheless, an interdisciplinary approach, including various expert profiles and their collaboration, with specific individualized treatments for patients and their families, is advised as the best DM treatment option ${ }^{21}$.

\section{CONCLUSION}

Symptoms of anxiety and depressive disorders frequently co-occur with DM in children and adolescents, and seem to be associated with significant medical complications, poor treatment adherence, and consequently impaired quality of life. The relationship between anxiety and depressive symptoms with DM is still not quite clear, but with various biological, psychological, and environmental links. Mental health screening and interventions aimed at treating anxiety and depressive disorders in children and adolescents suffering from DM should be an added approach, in addition to medical treatment of DM.

It is important to state that medical workers, along with the treatment of DM and co-occurring conditions, should also address the overall quality of life in all its aspects. It is important to pay attention to the lifestyle of children suffering from DM. Giving that a chronic disease can affect leisure activities and social activities in a negative manner, it is important that medical interventions occupy a minimum, yet necessary, part of children's daily routine. 


\section{Acknowledgments}

We would like to thank the Skaraborg's Hospital Library in Skövde, Sweden, for all of their help during the process of literature gathering.

Conflicts of interest statement: the authors report no conflicts of interest.

\section{REFERENCES}

1. American Diabetes Association. Diagnosis and Classification of Diabetes Mellitus. Diabetes Care 2009;32:S62-7.

2. International Diabetes Federation. IDF Diabetes Atlas. $7^{\text {th }}$ Edition. Brussels: International Diabetes Federation, 2015. Online version of IDF Diabetes Atlas [cited 2017 Oct 30]. Available from: http://www.diabetesatlas.org.

3. Cameron FJ, Northam EA. Screening for psychological disorders in youth with Type 1 diabetes: who, when, what and how? Diabetes Manag 2012;2:513-20.

4. Akbaş S, Karabekiroğlu K, Ŏzgen T, Tasdemir G, Karakurt $M$, Şenses $A$ et al. Association between emotional and behavioral problems and metabolic control in children and adolescents with Type 1 diabetes. J Endocrinol Invest 2009;32:325-9.

5. Northam EA, Lin A, Finch S, Werther GA, Cameron FJ. Psychosocial well-being and functional outcomes in youth with Type 1 diabetes 12 years after disease onset. Diabetes Care 2010;33:1430-7.

6. Dantzer C, Swendsen J, Maurice-Tison S, Salamon R. Anxiety and depression in juvenile diabetes: A critical review. Clin Psycho Rev 2003;23:787-800.

7. American Psychiatric Association. Diagnostic and Statistical Manual of Mental Disorders. $5^{\text {th }}$ Edition. Arlington, VA: American Psychiatric Pub, 2013, 155-235.

8. Grey M, Whittemore R, Tamborlane W. Depression in type 1 diabetes in children: Natural history and correlates. J Psychosom Res 2002;53:907-11.

9. Littlefield CH, Craven JL, Rodin GM, Daneman D, Murray MA, Rydall AC. Relationship of self-efficacy and binging to adherence to diabetes regimen among adolescents. Diabetes Care 1992;15:90-4.

10. LaGreca AM, Swales T, Klemp S, Madigan S, Skyler J. Adolescents with diabetes: Gender differences in psychosocial functioning and glycemic control. Child Health Care, 1995;24:61-78.

11. Grey M, Boland EA, Yu C, Sullivan-Bolyai S, Tamborlane $W V$. Personal and social factors associated with quality of life in adolescents with IDDM. Diabetes Care 1998;21:909-14.

12. Goldston DB, Kelley AE, Reboussin DM, Daniel SS, Smith JA, Schwartz RP et al. Suicidal ideation and behavior and noncompliance with the medical regimen among diabetic adolescents. J Am Acad Child Adolesc Psychiatry 1997;36:1528-36.

13. Ingerski LM, Anderson BJ, Dolan LM, Hood KK. Blood glucose monitoring and glycemic control in adolescence: Contribution of diabetes-specific responsibility and family conflict. J Adolesc Health 2010;47:191-7.

14. Goldston DB, Kovacs M, Ho VY, Parrone PL, Stiffler L. Suicidal ideation and suicide attempts among youth with insulin-dependent diabetes mellitus. J Am Acad Child Adolesc Psychiatry 1994;33:240-6.
15. Mutlu EK, Mutlu C, Taskiran H, Ozgen IT. Association of physical activity level with depression, anxiety, and quality of life in children with type 1 diabetes mellitus. J Pediatr Endocrinol Metab 2015;28:1273-8.

16. Kokkonen K, Kokkonen ER. Mental health and social adaptation in young adults with juvenile-onset diabetes. Nord J Psychiatry 1995;49:175-81.

17. Kovacs M, Goldston D, Obrosky DS, Bonar LK. Psychiatric disorders in youth with IDDM: Rates and risk factors. Diabetes Care 1997;20:36-44.

18. Reynolds KA, Helgeson VS. Children with Diabetes Compared to Peers: Depressed? Distressed? Ann Behav Med 2011;42:29-41.

19. Buchberger B, Huppertz H, Krabbe L, Lux B, Mattivi JT, Siafarikas A. Symptoms of depression and anxiety in youth with type 1 diabetes: A systematic review and meta-analysis. Psychoneuroendocrinology 2016;70:70-84.

20. Herzer M, Vesco A, Ingerski LM, Dolan LM, Hood KK. Explaining the family conflict-glycemic control link through psychological variables in adolescents with type 1 diabetes. J Behav Med 2011;34:268-74.

21. Delamater AM. Psychological care of children and adolescents with diabetes. Pediatr Diabetes 2009;10:175-84.

22. Baucom KJW, Queen TL, Wiebe D, Turner SL, Wolfe KL, Godbey El et al. Depressive Symptoms, Daily Stress, and Adherence in Late Adolescents with Type 1 Diabetes. Health Psychol 2015;34:522-30.

23. Plener PL, Molz E, Berger G, Schober E, Mönkemöller K, Denzer $\mathrm{C}$ et al. Depression, metabolic control, and antidepressant medication in young patients with type 1 diabetes. Pediatr Diabetes 2015;16:58-66.

24. Kanner S, Hamrin V, Grey M. Depression in adolescents with diabetes. J Child Adolesc Psychiatr Nurs 2003; 16:15-24.

25. Zheng XP, Chen SH. Psycho-behavioral changes in children with type 1 diabetes mellitus. World J Pediatr 2013;9:261-5.

26. Brazeau AS, Nakhla M, Wright M, Panagiotopoulos C, Pacaud D, Henderson $M$ et al. Stigma and Its Impact on Glucose Control Among Youth With Diabetes: Protocol for a Canada-Wide Study. JMIR Res Protoc [Internet]. 2016;5. [cited 2016 Dec 15]. Available from: https:// w w w . n c bi . n I m . n i h.gov/p m c/articles/ PMC5200843/?report=reader.

27. Ceylan C, Altay N. Social anxiety levels and associated factors among adolescents with type 1 diabetes compared with healthy peers. J Spec Pediatr Nurs [Internet]. 2017;22. [cited 2017 Jan 23]. Available from: http://onlinelibrary.wiley.com/doi/10.1111/ jspn.12172/epdf.

28. Doherty Y, Dovey-Pearce G. Understanding the developmental and psychological needs of young people with diabetes. Pract Diab Int 2005;22:59-64.

29. Thapar A, Collishaw S, Pine DS, Thapar AK. Depression in adolescence. Lancet 2012;379:1056-67.

30. Vila G, Robert JJ, Nollet-Clemencon C, Vera L, Crosnier $\mathrm{H}$, Rault $\mathrm{G}$ et al. Eating and emotional disorders in adolescent obese girls with insulin-dependent diabetes mellitus. Eur Child Adolesc Psychiatry 1995;4:270-9.

31. Gomez-Baya D, Mendoza R, Paino S, Gillham JE. A twoyear longitudinal study of gender differences in responses to positive affect and depressive symptoms during middle adolescence. J Adolesc 2017;56:11-23. 
32. Butler JM, Berg CA, King P, Gelfand D, Fortenberry K, Foster $C$ et al. Parental negative affect and adolescent efficacy for diabetes management. J Fam Psychol 2009; 23:611-4.

33. Fritsch SL, Overton MW, Robbins DR. The interface of child mental health and juvenile diabetes mellitus. Child Adolesc Psychiatr Clin N Am 2010;19:335-52.

34. Jönsson L, Lundqvist P, Tiberg I, Hallström I. Type 1 diabetes - impact on children and parents at diagnosis and 1 year subsequent to the child's diagnosis. Scand J Car Sci 2015;29:126-35.

35. Butler JM, Skinner M, Gelfand D, Berg CA, Wiebe DJ. Maternal parenting style and adjustment in adolescents with type 1 diabetes. J Pediatr Psychol 2007;32: 1227-37.

36. Barber BK, Stolz HE, Olsen JA, Collins WA, Burchinal M. Parental support, psychological control, and behavioral control: Assessing relevance across time, culture, method. Monogr Soc Res Child Dev 2005;70:1-137.

37. Gruhn MA, Lord JH, Jaser SS. Collaborative and Overinvolved Parenting Differentially Predict Outcomes in Adolescents With Type 1 Diabetes. Health Psychol 2016;35:652-62.

38. Wiebe DJ, Berg CA, Korbel C, Palmer DL, Beveridge RM, Upchurch R et al. Children's appraisals of maternal involvement in coping with diabetes: Enhancing our understanding of adherence, metabolic control, and quality of life across adolescence. J Pediat Psychol 2005;30:167-78.

39. McKee L, Roland E, Coffelt N, Olson AL, Forehand R, Massari $\mathrm{C}$ et al. Harsh discipline and child problem behaviors: The roles of positive parenting and gender. J Fam Violence 2007;22:187-96.

40. Malerbi FEK, Negrato CA, Gomes MB; Brazilian Type 1 Diabetes Study Group (Braz Diab 1 SG). Assessment of psychosocial variables by parents of youth with type 1 diabetes mellitus. Diabetol Metab Syndr [Internet]. 2012;4. [cited 2012 Nov 22]. Available from: https:// www.ncbi.nlm.nih.gov/pmc/articles/PMC3538713/.

41. Jaser SS, Whittemore R, Ambrosino JH, Lindemann E, Grey M. Mediators of depressive symptoms in children with type 1 diabetes and their mothers. J Pediatr Psychol 2008;33:509-19.

42. Wiebe DJ, Gelfand D, Butler JM, Korbel C, Fortenberry $\mathrm{KT}, \mathrm{McCabe} \mathrm{JE}$ et al. Longitudinal associations of maternal depressive symptoms, maternal involvement and diabetes management across adolescence. J Pediatr Psychol 2011;36:837-46.

43. Maas-van Schaaijk NM, Roeleveld-Versteegh ABC, van Baar AL. The Interrelationships among Paternal and Maternal Parenting Stress, Metabolic Control, and Depressive Symptoms in Adolescents with Type 1 Diabetes Mellitus. J Pediatr Psychol 2013;38:30-40.

44. Bădescu SV, Tătaru C, Kobylinska L, Georgescu EL, Zahiu DM, Zăgrean AM et al. The association between diabetes mellitus and depression. J Med Life 2016;9:120-5.

45. Borg H, Gottsäter A, Landin-Olsson M, Fernlund P, Sundkvist G. High Levels of Antigen-Specific Islet Antibodies Predict Future b-Cell Failure in Patients with Onset of Diabetes in Adult Age. J Clinic Endocrinol Metabo 2001; 86:3032-8.

46. Kongkaew C, Jampachaisri K, Chaturongkul CA, Scholfield CN. Depression and adherence to treatment in dia- betic children and adolescents: a systematic review and meta-analysis of observational studies. Eur J Pediatr 2014;173:203-12.

47. Irving RR, Mills JL, Choo-Kang EG, McLaughlin W, Wright-Pascoe R, Morrison EY et al. Diabetes and psychological co-morbidity in children with a family history of early-onset type 2 diabetes. Int J Psychol 2008;43: 937-42.

48. Brown LC, Majumdar SR, Newman SC, Johnson JA. History of depression increases risk of type 2 diabetes in younger adults. Diabetes Care 2005;28:1063-7.

49. Yu M, Zhang X, Lu F, Fang L. Depression and Risk for Diabetes: A Meta-Analysis. Can J Diabetes 2015;39:266-72.

50. Schwartz DD, Axelrad ME, Cline VD, Anderson BJ. A Model Psychosocial Screening Program for Children and Youth with Newly Diagnosed Type 1 Diabetes: Implications for Psychologists across Contexts of Care. Prof Psychol Res Pr 2011;42:324-30.

51. Delamater AM, de Wit M, McDarby V, Malik J, Acerini $\mathrm{CL}$. Psychological care of children and adolescents with type 1 diabetes. Pediatr Diabetes 2014;15:232-44.

52. Ortiz MS, Myers HF. Association between psychological stress and metabolic control in patients with type 1 diabetes mellitus. Rev Med Chile 2014;142:451-7.

53. Stewart SM, Rao U, Emslie GJ, Klein D, White PC. Depressive symptoms predict hospitalization for adolescents with type 1 diabetes mellitus. Pediatrics 2005;115: 1315-9.

54. McGrady ME, Peugh JL, Hood KK. Illness representations predict adherence in adolescents and young adults with type 1 diabetes. Psychol Health 2014;29:985-98.

55. Petitti DB, Klingensmith GJ, Bell RA, Andrews JS, Dabelea $D$, Imperatore $G$ et al. Glycemic control in youth with diabetes: the SEARCH for diabetes in Youth Study. J Pediatr 2009;155:668-72.

56. Bryden KS, Peveler RC, Stein A, Neil A, Mayou RA, Dunger DB. Clinical and psychological course of diabetes from adolescence to young adulthood: A longitudinal cohort study. Diabetes Care 2001;24:1536-40.

57. Leventhal H, Bodnar-Deren S, Breland JY, Hash-Converse J, Phillips LA, Leventhal EA et al. Modeling health and illness behavior: The approach of the common-sense model. In: Baum A, Revenson TA, Singer J (eds.). Handbook of health psychology. $2^{\text {nd }}$ Edition. New York: Psychology Press, 2012;3-35.

58. Harvey JN, Lawson VL. The importance of health belief models in determining self-care behaviour in diabetes. Diabet Med 2009;26:5-13.

59. Williams C, Sharpe L, Mullan B. Developmental challenges of adolescents with type 1 diabetes: The role of eating attitudes, family support and fear of negative evaluation. Psychol Healt Med 2014;19:324-34.

60. Stevanović D, Dejenie Habtewold T, Nikšić A, Avicenna $M$, Mehta G, Popović $L$ et al. Anxiety and depressive disorders in diabetes. In: Tripathi K, Saboo B (eds). Sadikot's Textbook of Diabetes. New Delhi: JP Medical, In press.

61. Petrak F, Herpertz S, Albus C, Hermanns N, Hiemke C, Hiller W et al. Cognitive Behavioral Therapy Versus Sertraline in Patients With Depression and Poorly Controlled Diabetes: The Diabetes and Depression (DAD) Study: A Randomized Controlled Multicenter Trial. Diabetes Care 2015;38:767-75. 
62. Pietrzyk-Orkisz K, Jozefacka-Majewska K, Zajaczkowska M, Galecki P. Treatment of Depression in Patients with Diabetes Mellitus: A Review. Med Sci Tech 2016;57: 110-5.

63. Baumeister $\mathrm{H}$, Hutter N, Bengel J. Psychological and pharmacological interventions for depression in patients with diabetes mellitus: an abridged Cochrane review. Diabet Med 2014;31:773-86.

64. Goodnick PJ. Use of antidepressants in treatment of comorbid diabetes mellitus and depression as well as in diabetic neuropathy. Ann Clin Psychiatry 2001;13:31-41.

65. Cipriani A, Zhou X, Del Giovane C, Hetrick SE, Qin B, Whittington $C$ et al. Comparative efficacy and tolerability of antidepressants for major depressive disorder in children and adolescents: a network meta-analysis. Lancet 2016;388:881-90.

66. Boričević Maršanić $V$, Aukst Margetić, B, Margetić B. Outpatient treatment of children and adolescents with antidepressants in Croatia. Int J Psychiatry Clin Pract 2012;16:214-22.

67. Maindal HT, Sandbæk A, Kirkevold M, Lauritzen T. Effect on motivation, perceived competence, and activation after participation in the "Ready to Act" programme for people with screen-detected dysglycaemia: A 1-year randomized controlled trial, Addition-DK. Scand J Pubic Health 2011;39:262-71.

68. Attari M, Sartippour M, Amini M, Haghighi S. Effect of stress management training on glycemic control in patients with type 1 diabetes. Diabetes Res Clin Pract 2006;73:23-8.

69. Soo H, Lam S. Stress management training in diabetes mellitus. J Health Psychol 2009;14:933-43.

70. Bitsko MJ, Bean MK, Bart S, Foster HR, Thacker L, Francis GL. Psychological Treatment Improves Hemoglobin A1c Outcomes in Adolescents with Type 1 Diabetes MeIlitus. J Clin Psychol Med Settings 2013;20:333-42.

71. Corey G. Theory and Practice of Counselling and Psychotherapy. $8^{\text {th }}$ Edition. Belmont: Thomson Higher Education, 2009;272-311.

72. Zhou X, Hetrick SE, Cuijpers P, Qin B, Barth J, Whittington $\mathrm{CJ}$ et al. Comparative efficacy and acceptability of psychotherapies for depression in children and adolescents: A systematic review and network meta-analysis. World Psychiatry 2015;14:207-22.

73. Maas-van Schaaijk NM, Roeleveld-Versteegh ABC, Odink RRJ, van Baar AL. Behavioral Problems and Depressive Symptoms in Adolescents with Type 1 Diabetes Mellitus: Self and Parent Reports. In: Oguntibeju OO (ed). Diabetes Mellitus - Insights and Perspectives InTech 2013. [cited 2013 Jan 23]. Available from: https:// www.intechopen.com/books/diabetes-mellitus-insights-and-perspectives/behavioral-problems-and-depressive-symptoms-in-adolescents-with-type-1-diabetes-mellitus-self-and-pa.

74. Lloyd CE, Brown FJ. Depression and diabetes. Curr Women's Health Rep 2002;2:188-93.

75. Ahmadi S, Tabibi Z, Mashhadi A, Eshraghi P, Faroughi F, Ahmadi P. Effectiveness of Group Cognitive-Behavioral Therapy on Anxiety, Depression and Glycemic Control in Children with Type 1 Diabetes. Int J Pediatr 2014;2: 165-71.

76. Rossello JM, Jiménez-Chafey MI. Cognitive-Behavioral Group Therapy for Depression in Adolescents with Diabetes: A Pilot Study. Interam J Psychol 2006;40:219-26.
77. Shomaker LB, Kelly NR, Radin RM, Cassidy OL, Shank LM, Brady SM et al. Prevention of insulin resistance in adolescents at risk for type 2 diabetes with depressive symptoms: 1-year follow-up of a randomized trial. Depress Anxiety 2017;34:866-76.

78. Uchendu C, Blake H. Effectiveness of cognitive-behavioural therapy on glycaemic control and psychological outcomes in adults with diabetes mellitus: a systematic review and meta-analysis of randomized controlled trials. Diabet Med 2017;34:328-39.

79. Markowitz JC, Weissman MM. Interpersonal psychotherapy: principles and applications. World Psychiatry 2004;3:136-9.

80. Zhou X, Hetrick SE, Cuijpers P, Qin B, Barth J, Whittington $\mathrm{CJ}$ et al. Comparative efficacy and acceptability of psychotherapies for depression in children and adolescents: a systematic review and network meta-analysis. World Psychiatry 2015;14:207-22.

81. Channon S, Smith VJ, Gregory JW. A pilot study of motivational interviewing in adolescents with diabetes. Arch Dis Child 2003;88:680-3.

82. Rossello J, Bernal G. The efficacy of cognitive-behavioral and interpersonal treatments for depression in $\mathrm{Pu}$ erto Rican adolescents. J Consult Clin Psychol 1999;67: 734-45.

83. Grey M, Boland EA, Davidson M, Yu C, Sullivan-Bolyai S, Tamborlane WV. Short-term effects of coping skills training as adjunct to intensive therapy in adolescents. Diabetes Care 1998;21:902-8.

84. Massengale J. Depression and the Adolescent with type 1 Diabetes: The Covert Comorbidity. Issues Ment Health Nurs 2009;26:137-48.

85. Kassiou K, Tsamasiros J. Family management of insulindependent diabetes mellitus: A practical problem-solving approach. Acta Paediatr Suppl 1999;88:47-51.

86. Anderson BJ, Svoren B, Laffel L. Initiatives to promote effective self-care skills in children and adolescents with diabetes mellitus. Dis Manage Health Outcomes 2007;15:101-8.

87. Helgeson VS, Reynolds KA, Escobar O, Siminerio L, Becker $D$. The role of friendship in the lives of male and female adolescents: Does diabetes make a difference? J Adolesc Health 2007;40:36-43.

88. van der Stouwe T, Asscher JJ, Stams GJJM, Dekovic M, van der Lann PH. The effectiveness of multisystemic theapy (MST): A meta-analysis. Clinical Psychology Review 2014;34:468-81.

89. Weaver K. Eating disorders in people with type 1 diabetes. Nursing Standard 2012;26:43-7.

90. Hauge L. The Importance of Managing Adolescent Mental Health when Diagnosed with Type 1 Diabetes: A Review of Current Literature. Richfield: The Faculty of the Adler Graduate School, 2015. A Master's Project.

91. Birmaher B, Brent D; AACAP Work Group on Quality Issues. Practice parameter for the assessment and treatment of children and adolescents with depressive disorders. J Am Acad Child Adolesc Psychiatry 2007;46: 1503-26.

92. Connolly SD, Bernstein GA; Work Group on Quality Issues. Practice parameter for the assessment and treatment of children and adolescents with anxiety disorders. J Am Acad Child Adolesc Psychiatry 2007;46: 267-83. 